\title{
The Emergence and Effects of Culturally Congruent Leadership: Current Status and Future Developments
}

\author{
Ghulam Mustafa, Rune Lines
}

\section{A B S T R A C T}

Objective: The purpose of this paper is to provide a critical assessment of the crosscultural leadership literature and suggest avenues for future developments on both empirical and conceptual fronts.

Research Design \& Methods: The paper performs a comprehensive review of the cross-cultural leadership literature with a particular focus on the emergence and effects of culturally congruent leadership. The paper identifies gaps and suggests a sequence of steps for future research.

Findings: The major focus of cross-cultural leadership studies has been on the measurement and description of relationships and research within this area has generally paid less attention to addressing other important issues such as cultural value effects across levels, interaction between individual and societal values, and the way cultureleadership congruity is produced and its effects are transmitted.

Implications \& Recommendations: The gaps identified and suggestions provided may be of value in theory development and integration, and in addressing empirical issues beyond measurement and description of relationships.

Contribution \& Value Added: Although prior studies offer reviews on effects of culture on organizationally relevant outcomes, but their analyses mainly focus on general categories of attitudes and behaviours. The focus of this paper is on providing a comprehensive assessment of the literature on the culture-leadership link.

\begin{tabular}{ll}
\hline Article type: & literature review \\
Keywords: & $\begin{array}{l}\text { culture; cultural congruence; cross-cultural leadership; organizations; } \\
\text { leadership }\end{array}$ \\
JEL codes: & M10, M50
\end{tabular}

\section{Suggested citation:}

Mustafa, G., \& Lines, R. (2016). The Emergence and Effects of Culturally Congruent Leadership: Current Status and Future Developments. Entrepreneurial Business and Economics Review, 4(1), 161180, DOI: http://dx.doi.org/10.15678/EBER.2016.040110 


\section{INTRODUCTION}

Cross-cultural leadership research has long recognized the importance of understanding cultural differences in the leadership process. Many such studies have stressed strong connection between leadership factors and societal norms and values (Hofstede, 1980b; House, Hanges, Javidan, Dorfman, \& Gupta, 2004; Javidan \& House, 2001; Pillai, Scandura \& Williams, 1999; Scandura \& Dorfman, 2004). The findings of many empirical studies reveal that leaders tend to behave in a manner that is consistent with the expectations of their respective societies, and the congruency between leadership behaviours and the societal norms and expectations is an important determinant of the leadership success (Dorfman, Sully de Luque, Hanges, \& Javidan, 2010). Together, the research findings within this area lend credence to the culture specific view of leadership by showing culture as a causal variable affecting the level of leader behaviors and its role as a moderator of leadership effects (Elenkov \& Manev, 2005; Geletkanycz, 1997; Offerman \& Hellmann, 1997).

However, the major focus of cross-cultural leadership studies has been on the measurement and description of relationships. Research within this area has generally paid less attention to addressing other important issues such as cultural value effects across levels, interaction between individual and societal values, and the way culture-leadership congruity is produced. Given the current state of the literature, there are several opportunities for extending our understanding of the link between cultural values and leadership on both empirical and conceptual fronts.

This paper attempts to provide a critical assessment of the field and suggests a sequence of steps for future research. The paper begins with a brief discussion of the societal and individual level conceptualizations of culture. This section provides the backdrop for subsequent discussions by illustrating the complexity of the concept of culture. Then the nature of the relationship between culture and leadership is considered, followed by a brief review of research on direct effects of culture on the behaviours exhibited by leaders and culture as a moderator of leadership effects. Thereafter, the importance of addressing relationships across levels is highlighted, followed by a discussion on the interaction. The word should be interaction between individual and societal level cultural values. The final section discusses research on the processes through which culturally congruent leadership is produced, and how culturally congruent leadership effects are realized in terms of leader effectiveness. The paper concludes with an indication of gaps in the existing literature and suggests potential avenues for future developments.

\section{REVIEW AND ASSESSMENT OF LITERATURE}

\section{Culture: Meaning and Levels of Conceptualization}

\section{Societal-Level Conceptualization of Culture}

Culture is a variously defined concept, but generally it is argued that culture comprises shared values and conceptions that come into being as a consequence of the common experiences of members of different social groups (House et al., 1999). According to Peterson and Anand (2004), culture consists of a relatively stable set of inner values and beliefs generally held by collectives in countries or regions and these inner values leave clear imprints on the people's outward behaviours and environment. According to Hofstede, 
i.e. (1980a) culture refers to observable patterns of cognitive structures that are unique to different social groups and are shaped by individuals' collective experiences. To the extent that individuals share common experiences, they will develop similar cognitive and behavioural profiles.

Cross-cultural studies have divergent views on the definition of culture, but there is a broad consensus among scholars that culture is a system of shared values that guide behaviour and provide a means for constructing and attributing meaning (Hofstede, 1980a; House et al., 2004; Schwartz, 1994). These studies suggest that societal cultures have unique characteristics and they differ from one another along certain value dimensions (e.g., Hofstede, 1980a). These value dimensions are seen as representing the socially shared ideas of what is desirable or good and right in a society (Smith \& Schwartz, 1997). Several researchers have proposed dimensions of societal culture (House et al., 2004; Inglehart \& Baker, 2000; Schwartz, 1994; Trompenaars, 1993), however, Hofstede's (1980a, 2001) cultural framework has become the most dominant of all cultural classifications. The cultural framework developed by Hofstede (1980a) consists of five dimensions: individualism-collectivism, power distance (PD), uncertainty avoidance (UA), masculinity-femininity, and future orientation. Earlier studies argue that Hofstede's framework has had far greater impact than other conceptualizations (Sivakumar \& Nakata, 2001), and researchers have used it as the primary theoretical perspective to understand cultural differences because of its clarity and parsimony (Kirkman, Lowe, \& Gibson, 2006).

The GLOBE (House et al., 1999, 2004) study operationalized nine cultural value dimensions: the first seven dimensions, i.e., UA, PD, collectivism-individualism, gender egalitarianism, assertiveness and future orientation have their roots in the dimensions of culture posited by Hofstede (1980a). The authors identified humane orientation and performance orientation as two additional dimensions. Unlike Hofstede, House et al. $(1999,2004)$ assessed collectivism-individualism values using in-group collectivism dimension and institutional collectivism dimension. Moreover, they substituted Hofstede's masculinity-femininity dimension with two cultural dimensions labelled as gender egalitarianism and assertiveness.

Schwartz (1994) offered yet another conceptualization of how societal cultures vary in terms of their shared values. He theorized three sets of bi-polar dimensions of societal culture: embeddedness versus autonomy, hierarchy versus egalitarianism, and mastery versus harmony. Hofstede's and Schwartz's conceptualizations of societal culture show considerable convergence, with Schwartz's perspective and research magnifying Hofstede's conclusions rather than refuting them (Smith, Bond, \& Kagitcibasi, 2006).

The values-based framework has generally been favored to understand cultural characteristics of societies, but other researchers (Gelfand, Nishii, \& Raver, 2006; Gelfand et al., 2011) have taken a different approach. Gelfand and colleagues define societal culture in terms of tightness and looseness. The authors argue that societies' values and practices may help capture cultural differences, but the strength of social norms within societies and the societies' strength of sanctioning may offer a deeper understanding of cultural phenomena.

\section{A Bi-Level Analysis of Culture}

The conventional approach to measuring cultures is to capture individual responses on different cultural value dimensions and then aggregating them to the country-level scores. 
However, several other studies have called for an approach that embodies the assessment of cultural variables at the individual level (Sharma, 2010; Tyler, Lind, \& Huo, 2000) as manifested in the strength of a person's adherence to different cultural dimensions (Patterson, Cowley, \& Prasongsukarn, 2006; Triandis, 1995). According to Triandis (1995), the macro level cultural dimensions have an individual analogue meaning that the cultural syndromes evidenced at societal level may also manifest themselves at the individual level.

Researchers who advocate an individual level analysis of cultural values contend that utilizing only a country level approach does not capture intra-cultural variations that inevitably exist in every culture (Au \& Cheung, 2004; Matsumoto 2003; Ralston et al., 2009; Realo 2003; Straub, Loch, Evaristo, Karahanna, \& Srite, 2002). However, neither of the approaches provide a comprehensive framework for appreciating individual level behavior. The appropriate way may be to conceptualize culture at both societal and individual level. The societal level conceptualization of culture cannot not be rejected because culture in a national society plays an important function in organizing collective life by providing solutions to the problems of everyday activities (Baldwin, Faulkner, Hecht, \& Lindsley, 2006). It guides individuals by reducing the number of available interpretations of an event or person and in this way it gives order to the world. Individuals are constrained by societal culture in so far that in order to be accepted as group members, they need to conform to cultural standards, which reinforce learning and internalization of cultural values. Shared values are general guidelines that regulate the behaviour of members of a society, so that collective life is organized and individuals interact more smoothly (Smith \& Schwartz, 1997). However, individual members of a culture may not harbour cultural values to the same degree; their individual cultural orientations might be either congruent or discrepant with the larger societal culture in which they live. Thus, applying cultural typology at the individual level is reasonable because cultural dimensions may have an individual analogy (Triandis, 1995), and the values of an individual person may be identified in terms of the selected dimensions of culture (Donthu \& Yoo, 1998).

\section{Culture and Leadership Interface}

\section{Universal and Culture Specific Views of Leadership}

Leadership has been one of the most extensively studied topics in organizational research (Yukl, 1994), yet there remains a lack of consensus among scholars as to whether leadership processes are universal or reflect the culture in which they are found. Those who subscribe to a universal perspective consider leadership as a universal phenomenon, meaning that the core leadership concepts and processes are generalizable across cultures (Bass, 1985, 1997). Such a transcultural approach assumes that the key concepts of leadership will be similar across societies. Bass (1997) takes a universal position regarding the applicability of transformational leadership and suggests that such leadership will be conducive to better follower outcomes in both Western and non-Western setting. The notion of the generalizability of transformational leadership across cultures is partly supported by empirical evidence. For example, the findings of a few studies on leadership in Asian societies show that transformational leadership is linked to positive employee outcomes in Asia just as in Western countries (Bai, Li, \& Xi, 2012; Ishikawa, 2012). 
At the same time, there is a substantial volume of cross-cultural leadership literature that underscores the importance of the influence of national culture on leadership processes (Casimir, Waldman, Bartram, \& Yang, 2006; Hofstede, 1993; House et al., 1997; Javidan \& House, 2001; Pillai et al., 1999; Scandura \& Dorfman, 2004; Shackleton \& Ali, 1990). This body of research has dwarfed the universal perspective of leadership by showing that leader values, attitudes, behaviours, and efficacy differ across societal cultures (Boyacigiller \& Adler, 1991; Hofstede, 1980b). The claim that there are differences in leadership and managerial processes is founded on the assertion that societal norms and values influence the behaviour of individuals, groups, and organizations within societies on one hand, and the degree to which such behaviours are viewed as legitimate, acceptable, and effective on the other (Hofstede, 2001; Triandis, 1995).

Cross-cultural leadership research suggests a strong linkage between culture and leadership processes in that cultural forces influence the choice of behaviours exhibited by leaders and the effects of leadership. It has been argued that leader behaviours reflective of collective values tend to be more acceptable and effective than behaviours that represent conflicting values (Dorfman et al., 2012; Dorfman et al., 2010; Javidan et al., 2006; Javidan \& House, 2001). For example, managers in Asia place a strong emphasis on paternalistic behaviour and group-oriented activities (Dorfman \& Howell, 1988; Schweiger, Sandberg, \& Ragan, 1986), which is consistent with paternalistic power distance and ingroup collectivist values in Asian societies. Likewise, employees in gender egalitarian and low power distance societies tend to be more receptive to leader behaviours that are congruent with high scores on these dimensions (House et al., 2004).

There are certain other studies (Dorfman et al., 1997; Fu \& Yukl, 2000; Javidan \& Carl, 2005) that hold that both universal and culture specific perspectives are valid in the study of leadership across societies. These studies point out that universal leader behaviours exist, but certain leadership behaviours are more preferred than others in certain societies. Together, the above studies underscore the importance of understanding cultural differences in the leadership process.

\section{Societal-Level Effects}

The culture specific leadership view describes national culture as an important contextual factor that could directly influence the leadership process (Ardichvili \& Kuchinke, 2002; Brodbeck et al., 2000). Several studies argue that there is a direct effect of culture on leadership styles (Fu \& Yukl, 2000; Hanges, Lord, \& Dickson, 2000; House et al., 1997; Smith \& Peterson, 1988).

Based on a comprehensive literature review, Triandis (1994) concluded that cultural values could strongly influence the optimum leadership profile in a country. The author noted that employees in countries characterized by individualist values have a strong preference for freedom and autonomy, while employees in collectivist cultures favour ingroup harmony and security. Offerman and Hellmann (1997), in their study based on survey data representing 39 different countries, found that PD had a negative relationship with leader behaviours related to team building, delegation, approachability and leader communication; and UA had a positive link with leader control but was negatively related to other behaviours such as delegation and approachability. In a sample of middle managers representing 54 countries, House et al. (1999) found that collectivism had a positive association with team-oriented leadership, and UA and PD were negatively related to 
leader participative behaviour. A recent study on cultural tightness-looseness and perceptions of effective leadership revealed that cultural tightness is positively associated to the endorsement of autonomous leadership and negatively related to the endorsement of charismatic and team leadership (Aktas, Gelfand \& Hanges, 2015)

Cross-cultural leadership studies have also recognized that cultural differences may enhance or diminish the impact of leadership styles on employee outcomes (Elenkov, 1998; Elenkov \& Manev, 2005; Hofstede, 2001; House et al., 1997; Javidan et al., 2006). This argument suggests that employees with diverse cultural backgrounds tend to react differently to different aspects of the job (Robert, Probst, Martocchio, Drasgow, \& Lawler, 2000) and the success of leadership is dependent on an appropriate fit between leadership factors and the norms and values prevalent in a society (Dorfman et al., 2010). The underlying premise for this research is that values associated with a society's culture can shape beliefs about what behaviours, styles, skills, and personality traits characterize effective leadership (Javidan et al., 2006). Thus, followers' receptivity to certain leadership styles may be contingent upon the cultural context within which leadership is enacted (Gelfand, Bhawuk, Nishii, \& Bechtold, 2004). The findings of many cross-cultural leadership studies underscore the importance of fit between national culture and leadership. Based on his findings of a cross-cultural study, Elenkov (1998) argues that leadership behaviours are differentially acceptable and effective across cultures. The author suggests that people in egalitarian societies tend to prefer participative leadership, while in a high PD context, authoritarian and directive leadership is likely to be more acceptable and effective.

\section{Individual-Level Effects}

The majority of studies that have addressed the main effects of culture on leadership tend to relate leadership to shared rather than individual-level values. The expectation of link between individual-level values and leadership is founded on the premise that individuals are not just cultural robots. Even within each society, there is a range of value profiles that reflect individual idiosyncrasies such as heritage, personal and professional affiliations and socioeconomic level (Schwartz \& Bardi, 2001). The key values that are important to a person help him/her perceive a situation, and he/she will interpret and react to a given situation in the light of the priorities assigned to various values (Schwartz, 1996). Thus, it is increasingly insightful to identify individual differences among managers in the degree to which leadership styles can be traced to differences in individual level cultural orientations. There is a scarce number of studies that have examined the direct effect of individual level cultural values on leadership. For instance, Chan and Drasgow (2001) investigated the connections between horizontal individualism and vertical individualism and various dimensions of motivation to lead using samples of military recruits and junior college students in the US and Singapore. In a similar vein, Pillai and Meindl, (1998) examined the relationship between individual level collectivist values and leaders' charismatic behaviour and found that collectivism and charismatic leadership had a positive relationship.

Contrary to the prevailing wisdom to alter leadership behaviours to fit the cultural profile of a particular country in which leadership is performed, a few studies show evidence for the notion that follower individual level cultural values play an important role in the relationship between leadership and follower outcomes (Nahum-Shani \& Somech, 2011; Walumbwa \& Lawler, 2003). This research indicates that individual level cultural values act as potential facilitators or barriers for leadership effects by influencing follower 
positive or negative evaluation of different leadership behaviours (Farh, Hackett, \& Liang, 2007; Rubin, Munz, \& Bommer, 2005; Walumbwa, Lawler, \& Avolio, 2007; Wasti, 2003). Accordingly, it has been suggested that the degree to which leadership behaviour is conducive to follower positive outcomes depends to a greater extent on the congruity of such behaviour with a follower's cultural orientation (Walumbwa et al., 2007). Thus, to elicit positive reactions from followers, leaders need to learn how followers' individual level cultural values shape their reactions to leadership (Kirkman et al., 2009; Mustafa \& Lines, 2014).

\section{Cross-Level and Interaction Effects of Culture}

\section{Cross-Level Effects}

The importance of the main effects of culture on the leadership process has been well recognized by the previous research (Offerman \& Hellmann, 1997; Scandura \& Dorfman, 2004). However, previous studies on cross-cultural leadership have generally not offered a clear explication of the issues related to levels of analysis (Yammarino, Dionne, Chun, \& Dansereau, 2005). In cross-cultural leadership research, it is quite uncommon to investigate relationships from a cross-level perspective in a single study. For instance, the link between culture and leaders' innovative behaviours has been examined only at the country level (Elenkov \& Manev, 2005). Societal level culture may be related to innovative behaviours, but values at individual level might have stronger implications for such behaviours. The reason for this is that values that are related to one's freedom of thought, creativity and intellectual stimulation may be strongly influenced by personal idiosyncrasies such as intellectual capacities (Sternberg, 1999), and personality and social standing of the family (McCrae \& Costa, 1997) rather than by cultural norms. Although there might be societal norms in pursuing such activities, these norms may not entail strong societal judgments (Fisher, 2006).

Likewise, in many recent studies, the impact of collectivism and traditional values on leadership effects has been examined only at the individual level (Spreitzer, Perttula, \& Xin, 2005). Collectivist and traditional values may have implications for leadership at the individual level, given that every cultural dimension is likely to have an individual analogue (Triandis, 1995). But, investigating societal level effects is important because norms guiding individual affect and behaviour often develop at societal level. For instance, traditionality captures deference to authority originating from a societal frame of reference, carrying many cultural and moral overtones (Farh, Hackett, \& Liang, 2007). Traditional values reflect a moral obligation to fulfil the normative expectations of a prescribed role to preserve social harmony and advance collective interests (Schwartz, 1992). Like traditionality, collectivism also originates from a broader societal and familial frame of reference. Individuals in collectivist cultures are more attentive to the behavioural demands of the society and in order to gain social acceptance they engage in behaviours that are less discrepant from other societal members (Yaveroglu \& Donthu 2002). According to Bontempo and Rivero (1992), societal norms are more effective than individual values in predicting behaviour in collectivist cultures. The above suggests that societal culture will have a pronounced effect on individual behaviour in cultural contexts where values are more traditional and collectivist.

Culture can also have implications for leadership at both societal and individual levels of analysis. For instance, in masculine societies, high performance and achievement are 
strongly emphasized (Kale \& Barnes, 1992), and people who are less success-oriented are likely to be exploited. Thus, in relation to masculinity, it is important to fit in with the culturally dominant values to some degree. At the same time, it has been argued that masculinity, which reflects motives for success and advancement, is also manifest at the individual level (e.g., Spence, 1983; Mustafa \& Lines, 2014). Likewise, societal level PD has been argued to have a predictive ability on leadership processes (Hofstede, 1980a). Dorfman et al. (2012) contend that in cultures characterized by hierarchical values, employees are more accepting of leadership styles that involve issuing directives instead of consulting and empowering subordinates. Research by Kirkman et al. (2009) suggests that employee individual values regarding hierarchy in organizations exert a strong influence in shaping their reactions to their leaders' behaviours.

\section{Interaction between Societal and Individual-Level Values}

Individuals in all national societies encounter issues of conflicts and compatibilities between their individual value priorities and the values that are espoused at the societal level. National culture might encourage the activation of values that are in line with the cultural profile of the country, whereas values that run counter to those cultural priorities are discouraged (Schwartz, 1994). Smith and Schwartz (1997) contend that national culture influences the magnitude of the effects of individual values. Yielding to normative pressure even when a behaviour is not consistent with one's individually held values, weakens the value-behaviour relationship (Bardi \& Schwartz, 2003). According to Molinsky (2007), norms for a behaviour in a national society facilitate or make it impossible for an individual to act in a manner that corresponds to his or her personal value system. Taras, Kirkman, and Steel (2010) take a different line of reasoning to explain the effects of cultural values under different societal conditions. In their meta-analysis, the authors noted that cultural tightness strengthened the relationship between cultural values and outcomes for culturally tighter rather than culturally looser societies. Referring to such a moderating effect by cultural tightness, the authors contend that this is because of the lower flexibility afforded by tighter societies to its members in the expression of their cultural values and outcomes (Gelfand, Nishii, \& Raver, 2006)

The above studies provide a basis for suggesting that societal culture has the capacity to weaken or strengthen the relationship between individual values and behaviours, but their analyses focus on general categories of behaviours and do not investigate the interplay between leaders' individual-level values and societal culture. The effects of individual values are likely to be amplified when these correspond to particular societies' cultural characteristics. Such an accentuation might be due in part to a parallelism between leader individual values and the societal context and the cues that are provided and maintained in the societal context. This suggests that when a leader's personal values are consistent with societal norms, the society in which one enacts leadership will encourage the activation of such values, and the behavioural demands in the society will facilitate him/her to behave both appropriately and in accordance with his or her core system of values (Molinsky, 2007). On the other hand, when a leader's individually held values are inconsistent with the societal norms - that is, when the behaviour the leader must enact in order to act according to societal expectations conflicts with individual values - the individual effects are less likely be accentuated. For example, the effects of allocentric values will be ampli- 
fied in collectivist societies because allocentric characteristics are more likely to be mirrored in other societal members and thus reinforced or activated in a more collectivist societal context. Likewise, the effects of an individual orientation to UA orientation are more likely in societal contexts characterized by high UA, because such contexts provide few cues beneficial to novelty and experimentation, yet offer ample cues that activate riskavoiding tendencies.

\section{Leader-Society Congruence}

Over the last few decades, considerable research effort has been invested into understanding the ways through which culture can have an impact on leadership. Several studies argue that there is a direct effect of culture on leadership, suggesting that societal members internalize cultural values as they grow up in their cultures (Hanges, Lord, \& Dickson, 2000; Smith \& Peterson 1988). Cultural values and norms specify what behaviours are desirable for members of the culture in their relationships with others and, as such, culture also restricts the options of appropriate behaviours and actions available to leaders (Swidler, 1986; Yukl, 2006).

There are, however a few studies (House et al., 1997; House et al., 2004; Mustafa and Lines, 2013a) that have suggested various intervening processes through which the effects of societal culture are realized in terms of culturally congruent leadership. House et al (2004) argued that an important route via which culture may influence leadership is through its effects on the implicit leadership theories held by members of the society (Javidan \& Carl, 2005; Lord \& Maher, 1991). House and colleagues showed that individuals in a society tend to develop a common implicit theory of leadership that is a set of attributes and expectations used as parameters to evaluate their leaders. Thus, people in a particular culture are likely to develop a collective agreement on effective and ineffective leadership processes. Such agreements turn into social influences for the members to produce certain behavioural orientations (House et al., 1997), and as such, leaders tend to engage in behaviours that align with the respective societies' expectations (Dorfman, Sully de Luque, Hanges, \& Javidan, 2010).

Mustafa and Lines (2013a) suggest that the effects of societal values on leadership are mediated through processes such as value internalization, experiential learning and external regulation. These processes include an internal drive exerted by a leader's individual values to behave according to the norms and expectations of the native national culture; a leader's gradual learning of followers' values and developing behavioural alternatives consistent with followers' value systems; and a leader's behaving appropriately in response to the legitimizing effects of the society in which the leadership is enacted. In addition to proposing a culture-leadership link driven by the above processes, the study also explores the indirect effects of societal culture. It suggests that cultural value dimensions may exert influence on leadership-cultural congruity through interaction with the mediating processes and the strength of such congruity may vary in different cultural settings.

The above studies offer deep insights into how leadership styles become congruent with societies' culture, but for a more in-depth understanding of such congruency the rationales suggested need more theoretical density and conceptual clarity. For instance, House et al (2004) provide the justification that leaders tend to act in ways that match the expectations of their respective societies, because being members of the same society they share the group's implicit criteria for distinguishing between effective and ineffective 
leader attributes. This process may yield valid mental representations of follower values to the extent that leaders are similar to followers in this respect. One might expect a shared categorization process among the people of a particular society because they are socialized to fit in with the cultural milieu in which they are embedded. Likewise, one of the mechanisms suggested by Mustafa and Lines (2013a) is an experiential learning process by which leaders are thought to explore followers' values by observing their reactions, and subsequently develop behavioural alternatives presumed to be consistent with these value systems. Research on the formation and updating of implicit theories, in particular implicit person theories, indicates that this view is overly optimistic. Also the broader literature on learning in organizations has identified several ways in which known preconditions for the generation of valid knowledge often are violated in organizational settings (e.g., March \& Olsen, 1975). From the research on implicit person theories it is known that people often hold and defend highly simplistic models of others and such models are persistent even in the presence of experiences that seemingly contradict their content (e.g., Haslam, 2006). People have a general tendency to accord a simpler mental life to others, see others' behaviours as more driven by global dispositions than by contextual influences or rational deliberation, and often use self- knowledge to make inferences about others. This alludes to a link between leader personal values and their perception of follower values on the one hand, and a link between personal values and leadership behaviour on the other. Future studies might disentangle these processes and assess their relative contribution to the observed relationship between perceptions of follower values and leadership behaviour.

\section{Emergence of Leader-Society Value Congruence}

There is a broad consensus among researchers that societal culture plays an important role in shaping individual values and perceptions of societal members (e.g., Hofstede, 1980 b; Javidan \& House, 2001). However, the intensity of such influence is thought to differ across cultures. Convergence between individual and collective values is generally presumed to be high in collectivist, traditional and tight cultures because of a strong group focus and/or strength of social norms in such cultures. According to Triandis (1995), individuals in collectivist cultures tend to align their personal goals closely with the goals of the collective more than their counterparts in individualist cultures. Likewise, role obligations and other normative influences in traditional cultures are thought to influence the development of individuals' collective identity (Westwood, Chan \& Linstead, 2004). In such societies, people attempt to harmonize social expectations with individual preferences (Vauclair, 2009; Yao \& Wang, 2006), which tends to produce a close alignment between personal and societal values.

Gelfand and colleagues $(2006,2011)$ argue that culturally tighter societies offer less flexibility to its members in the expression of their individual attributes. On the other hand, individuals in loose cultures are allowed to exhibit greater variability in idiosyncrasies. As a result of differences in flexibility, individuals in culturally looser societies express high variance in attributes, while individuals in tights cultures tend to show greater homogeneity in individual attributes such as cultural values (Gelfand et al. 2006; Gelfand et al. 2011). This suggests that members in tight cultures might closely share norms and values that characterize their society. 
From the above studies it is evident that people's values and psychological tendencies develop in such a way that their overlap with societal values tends to be more salient in certain cultures compared to others. Conspicuously absent from these studies, however, is an attempt to provide a comprehensive explication of the mechanisms of how leaders' individual cultural values become congruent with the societal culture. An exception is Mustafa and Lines' (2015) study that has attempted to provide a conceptual framework of leader-society congruence by integrating the cultural dimensions, self-construal and communication pattern. However, the work needs more theoretical density for the following reasons. Congruence between a leader's individual cultural values and societal values is as important as incongruence between them. The significance of congruence depends on the limitations associated with incongruence. Therefore, it could enhance the theoretical rigor of the study if incongruence were also taken into account. That is, which cultural dimensions promote incongruence through self-construal and communication pattern?

\section{Leader-society Congruence Effects}

While cultural congruence is often assumed to contribute to the increased effectiveness of leaders, it is not clear what factors connect culturally congruent behaviour and follower positive outcomes. Many past studies have examined congruity between leadership and societal culture, but the bulk of this research (e.g., Dorfman, Hanges, \& Brodbeck, 2004; House et al., 2004; Javidan et al., 2006; Javidan \& Carl, 2004; Pasa, Kabasakal, \& Bodur., 2001) has mainly focused on assessing the effects of leadership-culture fit without offering conceptual clarification of the processes via which such effects are transmitted. Implicit leadership theory, which posits that leadership is understood by a cognitive categorization process through which individuals categorize the attributes that distinguish between effective and ineffective leaders (Den Hartog et al., 1999; Lord, Foti, \& De Vader, 1984; Phillips \& Lord, 1981) provides one of the major explanations of how leadership-culture congruence might result in positive outcomes. House et al (2004) extrapolate such categorization to societal level and suggest that members of a culture tend to develop a common implicit theory of leadership. The authors further argue that a leader is likely to have a high acceptance among the members of a culture, if his/her actions and attributes closely fit with the group's implicit criteria. It is, however, not clear how positive outcomes might result in acceptance of the leader as a result of a match between leadership behaviours and members' internal categories of leadership attributes. Does such acceptance lead to attraction for the leader, or it is because of enhanced trust, improved communication or some other processes that operate at affective or cognitive level?

Using the above logic of congruity of leader attributes to members' implicit criteria, Aktas, Gelfand and Hanges (2015) argue that leaders will be effective in different ways in tight and loose cultures. For instance, they suggest that charismatic and team leadership attributes will be perceived as more effective in loose (compared with tight) cultures. The study however seems to lack conceptual clarity for the following reasons. As argued by Gelfand et al. $(2006,2011)$, loose cultures are more accepting of discrepancy from societal norms. As such between-person variance in such cultures will be high in terms of individual attributes and expectations, and because of such divergence across individuals there will be greater variance in perceptions regarding what type of behaviour, attitudes and attributes might be seen as acceptable or unacceptable. Given the characteristics of loose cultures, it is unrealistic to expect that such cultures will have any significant effects on the 
development of shared categories of effective leadership prototypes. Thus, it seems farfetched to suggest that people in loose cultures will develop similar prototypes of effective leadership, and based on such a common categorization of the leadership attributes they will only be attracted to a certain set of leadership behaviours. Rather, one might expect much variance in people's categories of leadership attributes when judging whether leaders are effective or ineffective.

Drawing on the concept of value congruence, Mustafa and Lines (2013b) suggest that various mechanisms that link value congruence to organizational outcomes (Edwards \& Cable, 2009; Meglino \& Ravlin, 1998) may also be extrapolated to the societal level to present a clear picture of the effects of leadership-culture congruence. These authors argue that evaluating congruence along certain cultural dimensions may be more useful in addressing the issue of leadership-culture congruity effects for the following reasons. First, employees are more sensitive to what they sense than by what they see and hear (Fu et al., 2010). They will respond negatively if leaders just tailor their actions for smooth interaction but hold values that are inconsistent with fundamental cultural assumptions of followers. To leverage high levels of positive outcomes, cultural adaptation should transcend a temporary shift in one's frame of reference to integrating elements of the other culture into one's own. Secondly, congruence in cultural values may be more important for leaders in their relationship with followers than just behaving in a culturally correspondent way, because people tend to gradually shift their focus from readily detectible to deeper level attributes when they closely interact with others (e.g. Jackson, 1996). Thirdly, cultural adaptation is beyond tailoring one's behaviours but involves adjustment that results from touching deep-rooted cultural assumptions and dispositions. Thus, efforts to produce culturally congruent behaviours may be difficult to implement in a natural way and followers may suspect the sincerity of such efforts (Thomas \& Ravlin, 1995). Fourth, acting in a culturally consistent manner may lead to identity conflict if leaders' individually held values are highly incongruent with the values of the societies in which they operate (Molinsky, 2007).

Mustafa and Lines (2013b) provide a sophisticated view of the leader-society value congruence effects and the variance of these relationships across cultures; nonetheless, the study seems to have certain conceptual limitations. In discussion of the greater importance of congruence (and lack of variability) in some cultures compared to others, the authors suggest that in-group/out-group categorization is not evident in individualistic societies because such people place higher interest on personal agendas. It was concluded that managers with values more compatible with societal values would be a greater source of attraction for followers in collectivist cultures than for those from individualist cultures. Generally, this implies that people in individualistic cultures are more attracted to transactional leaders/managers. However, certain attributes of transformational leadership are known to be largely universally accepted across cultures (Den Hartog et al., 1999). Earlier empirical evidence has shown that transformational leadership was associated with positive outcomes both in collectivist (Lim \& Ployhart, 2004) and individualistic (Bass, Avolio, Jung, \& Berson, 2003) societies. Thus, the implication that transactional leadership is more related to individualist cultures does not seem to be supported.

Moreover, the study posits that the value of leader-society value congruence will be higher in some cultures than others because of the conducive effects of such cultures on 
interpersonal attraction, predictability and interpersonal communication. However, their theorizing seems to offer an incomplete picture of leader-society congruence effects in view of the earlier assertions that people in all cultures tend to have positive/negative evaluations of their leaders, but such evaluations are cognition-based in some cultures and inference-based in others (Lord \& Maher, 1991; Yan \&Hunt, 2005). Thus, it can be surmised that all cultures may promote the above mechanisms but the bases of these mechanisms may vary across societies. For instance, interpersonal attraction may lead to positive outcomes in both collectivist and individualist cultures, but people in collectivist cultures may develop an affect-based attraction while people in individualist cultures may develop a cognition-based attraction.

\section{CONCLUSIONS AND SUGGESTIONS FOR FUTURE RESEARCH}

Although the effects of cultural values on the leadership process have been well-documented, certain issues still need attention.

First, the existing cross-cultural leadership studies have stressed strong connection between leadership factors and the societal norms and values, but there have been negligible attempts to clarify these linkages in order to create a complete picture of how leadership styles become congruent with societies' culture. Thus, more theory development is needed to conceptually clarify the underlying processes that are responsible for producing correspondence between leadership styles and societal culture.

Second, the majority of studies that have addressed the culture-leadership linkage tend to relate leadership to societal rather than individual cultural orientation. The bulk of this research has tried to address the relationship between culture and leadership by capturing the degree to which managerial attitudes and behaviours vary across societies (e.g., Javidan \& Carl, 2004). The few studies that have examined the relationships at the individual level of analysis have mainly focused on testing direct and moderating effects of collectivist/individualist values. Beyond individualism-collectivism, only sparse attention has been invested in exploring the connections between other values and leadership.

Third, most studies in the field of cross-cultural leadership have concentrated on examining the relationship between culture and leadership at either societal or individual level, and there is a lack of research on different cultural value effects across levels (Yammarino et al., 2005). A few studies that have examined the cross level effects have used country as a proxy of culture (e.g., Kirkman et al., 2009). According to Kirkman et al. (2006), lack of research on cross-level effects of culture is due to the absence of sufficient theory about the effects of cultural values at both the individual and societal levels of analysis. Further, in the cross-cultural leadership domain, examining the interaction effects of cultural values at societal and individual level of analysis is incredibly rare. For example, none of the studies examined the moderating effects of societal level values on leaders' individually held cultural values as they relate to leadership behaviours. There exist no compelling theoretical reasons to suspect that societal and individual level cultural values exert influence on outcomes independent of each other. In fact, examining interactions among societal and individual level cultural values might provide insights into the complex relationship between the two levels of analysis. There may also be important cross level interactions among different cultural values. It is important to explore these interactions, because 
societal level culture seems to reinforce the effects of certain individual level variables and weaken the effects of certain others.

Moreover, the current literature does not provide a deeper understanding of the potential causal relationships between cultural context and member-society value congruence. Thus, little is known about how leaders' cultural orientations become congruent with the societal culture, and whether the degree to which leaders' individual level values correspond to the values of the larger society varies across cultures. Given the current state of literature, formulating theoretical rationales concerning how leader-society value congruence is produced and why in some cultures value congruence occurs more than others, is important.

Finally, the major focus of existing cross-cultural leadership studies has been on the practice-culture fit and its outcomes without conceptually clarifying how such congruence affects leadership success within and across cultures. There have been negligible attempts to draw on the concept of value congruence to provide explanations of the leader-society value congruence effects. Addressing the issue of congruity from the perspective of values may offer a deeper understanding of the underlying processes that potentially transmit the effects of leader-society congruence on outcomes.

\section{REFERENCES}

Adler, N.J. (1997). International dimensions of organizational behavior. Cincinnati, Ohio: SouthWestern College Publishing.

Aktas, M., Gelfand, M., \& Hanges, P. (2015). Cultural tightness-looseness and perceptions of effective leadership. Journal of Cross-Cultural Psychology, 0022022115606802.

Ardichvili, A., \& Kuchinke, K. P. (2002). Leadership styles and cultural values among managers and subordinates: a comparative study of four countries of the former Soviet Union, Germany, and the US. Human Resource Development International, 5(1), 99-117.

Arzu Wasti, S. (2003). The influence of cultural values on antecedents of organisational commitment: An individual-level analysis. Applied Psychology, 52(4), 533-554.

$\mathrm{Au}$, K., \& Cheung, M. L. (2004). Intra-cultural variation and job autonomy in 42 countries. Organization Studies, 25(8), 1339-1362.

Baack, D. W., \& Singh, N. (2007). Culture and web communications. Journal of Business Research, 60(3), 181-188.

Bai, Y., Li, P. P., \& Xi, Y. (2012). The distinctive effects of dual-level leadership behaviors on employees' trust in leadership: An empirical study from China. Asia Pacific Journal of Management, 29(2), 213-237.

Baldwin, J. R., Faulkner, S. L., Hecht, M. L., \& Lindsley, S. L. (2006). Redefining culture: Perspectives across the disciplines. Mahwah, NJ: Lawrence Erlbaum.

Bardi, A., \& Schwartz, S. H. (2003). Values and behavior: Strength and structure of relations. Personality and Social Psychology Bulletin, 29(10), 1207-1220.

Bass, B. M. (1985). Leadership and performance beyond expectations. New York: Free Press.

Bass, B. M. (1997). Does the transactional-transformational leadership paradigm transcend organizational and national boundaries? American Psychologist, 52(2), 130-139.

Bass, B. M., Avolio, B. J., Jung, D. I., \& Berson, Y. (2003). Predicting unit performance by assessing transformational and transactional leadership. Journal of Applied Psychology, 88(2): 207-218. 
Bontempo, R., \& Rivero, J. (1992). Cultural variation in cognition: The role of self-concept in the attitude-behavior link. Paper presented at the Academy of Management meeting, Las Vegas, Nevada.

Boyacigiller, N. A., \& Adler, N. J. (1991). The parochial dinosaur: Organizational science in a global context. Academy of Management Review, 16(2), 262-290.

Brodbeck, F. C., Frese, M., Akerblom, S., Audia, G., Bakacsi, G., Bendova, H., \& Brenk, K. (2000). Cultural variation of leadership prototypes across 22 European countries. Journal of Occupational and Organizational Psychology, 73(1), 1-29.

Casimir, G., Waldman, D. A., Bartram, T., \& Yang, S. (2006). Trust and the relationship between leadership and follower performance: Opening the black box in Australia and China. Journal of Leadership \& Organizational Studies, 12(3), 68-84.

Chan, K.Y., \& Drasgow, F. (2001). Toward a theory of individual differences and leadership: Understanding the motivation to lead. Journal of Applied Psychology, 86(3), 481-498.

Den Hartog, D. N., House, R. J., Hanges, P. J., Ruiz-Quintanilla, S. A., \& Dorfman, P. W. (1999). Culture specific and cross-culturally generalizable implicit leadership theories: Are attributes of charismatic/transformational leadership universally endorsed? The Leadership Quarterly, 10(2), 219-256.

Donthu, N., \& Yoo, B. (1998). Cultural influences on service quality expectations. Journal of Service Research, 1(2), 178-186.

Dorfman, P. W., \& Howell, J. P. (1988). Dimensions of National Culture \& Effective Leadership Patterns: Hofstede revisited Advances in international comparative management: $A$ research annual (pp. 127-149).

Dorfman, P. W., Howell, J. P., Hibino, S., Lee, J. K., Tate, U., \& Bautista, A. (1997). Leadership in Western and Asian countries: Commonalities and differences in effective leadership processes across cultures. The Leadership Quarterly, 8(3), 233-274.

Dorfman, P., Javidan, M., Hanges, P., Dastmalchian, A., \& House, R. (2012). GLOBE: A twenty year journey into the intriguing world of culture and leadership. Journal of World Business, 47(4), 504-518.

Dorfman, P. W., Sully de Luque, M., Hanges, P., \& Javidan, M. (2010). Strategic Leadership Across Cultures: The New GLOBE Multinational Study. Paper presented at the Academy of Management annual meeting, Montreal, Canada.

Edwards, J. R., \& Cable, D. M. (2009). The value of value congruence. Journal of Applied Psychology, 94(3), 654-677.

Elenkov, D. S. (1998). Can American management concepts work in Russia? California Management Review, 40(4), 133-156.

Elenkov, D. S., \& Manev, I. M. (2005). Top management leadership and influence on innovation: The role of sociocultural context. Journal of Management, 31(3), 381-402.

Farh, J.-L., Hackett, R. D., \& Liang, J. (2007). Individual-level cultural values as moderators of perceived organizational support-employee outcome relationships in China: Comparing the effects of power distance and traditionality. Academy of Management Journal, 50(3), 715-729.

Fischer, R. (2006). Congruence and functions of personal and cultural values: Do my values reflect my culture's values? Personality and Social Psychology Bulletin, 32(11), 1419-1431.

Franke, R. H., Hofstede, G., \& Bond, M. H. (1991). Cultural roots of economic performance: A research note. Strategic Management Journal, 12(S1), 165-173.

Fu, P. P., \& Yukl, G. (2000). Perceived effectiveness of influence tactics in the United States and China. The Leadership Quarterly, 11(2), 251-266. 
Fu, P. P., Tsui, A. S., Liu, J., \& Li, L. (2010). Pursuit of whose happiness? Executive leaders' transformational behaviors and personal values. Administrative Science Quarterly, 55(2), 222254.

Geletkanycz, M. A. (1997). The salience of 'culture's consequences': The effects of cultural values on top executive commitment to the status quo. Strategic Management Journal, 18(8), 615-634.

Gelfand, M., Bhawuk, D., Nishii, L., \& Bechtold, D. (2004). Individualism and collectivism. In R. House, P. Hanges, M. Javidan, P. Dorfman \& V. Gupta (Ed.), Culture, leadership, and organizations: The GLOBE study 62 societies (pp. 437-512). Thousand Oaks: Sage.

Gelfand, M. J., Nishii, L. H., \& Raver, J. L. (2006). On the nature and importance of cultural tightnesslooseness. Journal of Applied Psychology, 91(6), 1225-1244.

Haslam, N. (2006). Dehumanization: An integrative review. Personality and Social Psychology Review, 10(3), 252-264.

Hanges, P., Lord, R., \& Dickson, M. (2000). An Information-processing Perspective on Leadership and Culture: A Case for Connectionist Architecture. Applied Psychology, 49(1), 133-161.

Hofstede, G. (1980a). Culture's consequences: International differences in work-related values. Beverly Hills, CA: Sage.

Hofstede, G. (1980b). Motivation, leadership, and organization: Do American theories apply abroad? Organizational dynamics, 9(1), 42-63.

Hofstede, G. (1993). Cultural constraints in management theories. The Academy of Management Executive, 7(1), 81-94.

Hofstede, G. (2001). Culture's consequences: comparing values, behaviors, institutions, and organizations across nations. Thousand Oaks, CA: Sage.

House, R. J., Hanges, P. J., Ruiz-Quintanilla, S. A., Dorfman, P. W., Javidan, M., Dickson, M., \& Gupta, V. (1999). Cultural influences on leadership and organizations: Project GLOBE. Advances in Global Leadership, 1(2), 171-233.

House, R. J., Wright, N. S., \& Aditya, R. N. (1997). Cross-cultural research on organizational leadership. In P. C. Earley \& M. Erez (Ed.), New perspectives in international industrial organizational psychology (pp. 535-625). San Francisco: New Lexington.

House, R. J., Hanges, P. J., Javidan, M., Dorfman, P. W., \& Gupta, V. (2004). Leadership, culture, and organizations: The GLOBE study of 62 societies. Beverly Hills: Sage Publications.

Ishikawa, J. (2012). Transformational leadership and gatekeeping leadership: The roles of norm for maintaining consensus and shared leadership in team performance. Asia Pacific Journal of Management, 29(2), 265-283.

Javidan, M., Dorfman, P. W., De Luque, M. S., \& House, R. J. (2006). In the eye of the beholder: Cross cultural lessons in leadership from Project GLOBE. The Academy of Management Perspectives, 20(1), 67-90.

Javidan, M., \& House, R. J. (2001). Cultural acumen for the global manager: Lessons from project GLOBE. Organizational Dynamics, 29(4), 289-305.

Kale, S. H., \& Barnes, J. W. (1992). Understanding the domain of cross-national buyer-seller interactions. Journal of International Business Studies, 23(1), 101-132.

Kirkman, B. L., Chen, G., Farh, J.-L., Chen, Z. X., \& Lowe, K. B. (2009). Individual power distance orientation and follower reactions to transformational leaders: A cross-level, cross-cultural examination. Academy of Management Journal, 52(4), 744-764.

Kirkman, B. L., Lowe, K. B., \& Gibson, C. B. (2006). A quarter century of culture's consequences: A review of empirical research incorporating Hofstede's cultural values framework. Journal of International Business Studies, 37(3), 285-320. 
Lim, B.C., \& Ployhart, R. E. (2004). Transformational leadership: relations to the five-factor model and team performance in typical and maximum contexts. Journal of Applied Psychology, 89(4), 610-621.

Lord, R. G., Foti, R. J., \& De Vader, C. L. (1984). A test of leadership categorization theory: Internal structure, information processing, and leadership perceptions. Organizational behavior and human performance, 34(3), 343-378.

Lord, R. G., \& Maher, K. J. (1991). Leadership and information processing. Boston: Unwin Hyman.

March, J. G., \& Olsen, J. P. (1975). The uncertainty of the past: organizational learning under ambiguity. European Journal of Political Research, 3(2), 147-171.

Matsumoto, D. (2003). The discrepancy between consensual-level culture and individual-level culture. Culture \& Psychology, 9(1), 89-95.

McCrae, R. R., \& Costa Jr, P. T. (1997). Personality trait structure as a human universal. American Psychologist, 52(5), 509-516.

Meglino, B. M., \& Ravlin, E. C. (1998). Individual values in organizations: Concepts, controversies, and research. Journal of Management, 24(3), 351-389.

Molinsky, A. (2007). Cross-cultural code-switching: The psychological challenges of adapting behavior in foreign cultural interactions. Academy of Management Review, 32(2), 622-640.

Mustafa, G., \& Lines, R. (2013a). The triple role of values in culturally adapted leadership styles. International Journal of Cross Cultural Management, 13(1), 1-14.

Mustafa, G., \& Lines, R. (2013b). A cultural contingency model of the effects of leader-society value congruence. International Business Research, 6(10), 23-46.

Mustafa, G., \& Lines, R. (2014). Influence of leadership on job satisfaction: The moderating effects of follower individual-level masculinity-femininity values. Journal of Leadership Studies, 7(4), 23-39.

Mustafa, G. (2015). The emergence of leader-society value congruence: A cross-cultural perspective. The Journal of Values-Based Leadership, 8(2), 31-53.

Nahum-Shani, I., \& Somech, A. (2011). Leadership, OCB and individual differences: Idiocentrism and allocentrism as moderators of the relationship between transformational and transactional leadership and OCB. The Leadership Quarterly, 22(2), 353-366.

Niu, W., \& Sternberg, R. J. (2001). Cultural influences on artistic creativity and its evaluation. International Journal of Psychology, 36(4), 225-241.

Offermann, L. R., \& Hellmann, P. S. (1997). Culture's consequences for leadership behavior national values in action. Journal of Cross-Cultural Psychology, 28(3), 342-351.

Pasa, S., Kabasakal, H., \& Bodur, M. (2001). Society, organisations, and leadership in Turkey. Applied Psychology, 50(4), 559-589.

Patterson, P. G., Cowley, E., \& Prasongsukarn, K. (2006). Service failure recovery: the moderating impact of individual-level cultural value orientation on perceptions of justice. International Journal of Research in Marketing, 23(3), 263-277.

Peterson, R. A., \& Anand, N. (2004). The production of culture perspective. Annual Review of Sociology, 30: 311-334.

Pillai, R., \& Meindl, J. R. (1998). Context and charisma: A" meso" level examination of the relationship of organic structure, collectivism, and crisis to charismatic leadership. Journal of Management, 24(5), 643-671.

Pillai, R., Scandura, T. A., \& Williams, E. A. (1999). Leadership and organizational justice: Similarities and differences across cultures. Journal of International Business Studies, 30(49), 763-779. 
Phillips, J. S., \& Lord, R. G. (1981). Causal attributions and perceptions of leadership. Organizational behavior and human performance, 28(2), 143-163.

Ralston, D. A., Egri, C. P., De la Garza Carranza, M. T., Ramburuth, P., Terpstra-Tong, J., Pekerti, A. A., \& Tang, M. (2009). Ethical preferences for influencing superiors: A 41-society study. Journal of International Business Studies, 40(6), 1022-1045.

Realo, A. (2003). Comparison of public and academic discourses: Estonian individualism and collectivism revisited. Culture \& Psychology, 9(1), 47-77.

Remenyi, D., Williams, B., Money, A., \& Swartz, E. (1998). Doing research in business and management: an introduction to process and method. London: Sage.

Robert, C., Probst, T. M., Martocchio, J. J., Drasgow, F., \& Lawler, J. J. (2000). Empowerment and continuous improvement in the United States, Mexico, Poland, and India: Predicting fit on the basis of the dimensions of power distance and individualism. Journal of Applied Psychology, 85(5), 643-658.

Rubin, R. S., Munz, D. C., \& Bommer, W. H. (2005). Leading from within: The effects of emotion recognition and personality on transformational leadership behavior. Academy of Management Journal, 48(5), 845-858.

Scandura, T., \& Dorfman, P. (2004). Leadership research in an international and cross-cultural context. The Leadership Quarterly, 15(2), 277-307.

Schwartz, S. H. (1992). Universals in the content and structure of values: Theoretical advances and empirical tests in 20 countries. Advances in Experimental Social Psychology, 25(1), 1-65.

Schwartz, S. H. (1994). Are there universal aspects in the structure and contents of human values? Journal of Social Issues, 50(4), 19-45.

Schwartz, S. H. (1996). Value priorities and behavior: Applying a theory of integrated value systems. In C. Seligman, J.M. Olson, \& M.P. Zanna (Ed.), The psychology of values (pp. 1-24). Hillsdale, NJ: Erlbaum.

Schwartz, S. H., \& Bardi, A. (2001). Value hierarchies across cultures taking a similarities perspective. Journal of Cross-Cultural Psychology, 32(3), 268-290.

Schweiger, D. M., Sandberg, W. R., \& Ragan, J. W. (1986). Group approaches for improving strategic decision making: A comparative analysis of dialectical inquiry, devil's advocacy, and consensus. Academy of Management Journal, 29(1), 51-71.

Scott, W. R. (2008). Institutions and organizations. Thousand Oaks, CA: Sage.

Shackleton, V. J., \& Ali, A. H. (1990). Work-related values of managers: A test of the Hofstede model. Journal of Cross-Cultural Psychology, 21(1), 109-118.

Sharma, P. (2010). Measuring personal cultural orientations: scale development and validation. Journal of the Academy of Marketing Science, 38(6), 787-806.

Sivakumar, K., \& Nakata, C. (2001). The stampede toward Hofstede's framework: avoiding the sample design pit in cross-cultural research. Journal of International Business Studies, 32(3), 555-574.

Smith, P., \& Peterson, M. (1994). Leadership as event-management: A cross-cultural survey based upon middle-managers from 25 nations. Paper presented at International Congress of Applied Psychology, Madrid, Spain.

Smith, P. B., Bond, M. H., \& Kagitcibasi, C. (2006). Understanding social psychology across cultures: Living and working in a changing world. London: Sage.

Smith, P. B., \& Schwartz, S. H. (1997). Values. In J. W. Berry, M. H. Segall \& C. Kagitcibasi (Ed.), Handbook of cross-cultural psychology (pp. 77-108). Boston: Allyn \& Bacon. 
Spence, J. T. (1984). Masculinity, femininity, and gender-related traits: A conceptual analysis and critique of current research. In B. A.Maher \& W. B. Maher (Ed.), Progress in experimental personality research (pp. 1-97). Orlando, Florida: Academic.

Spreitzer, G. M., Perttula, K. H., \& Xin, K. (2005). Traditionality matters: An examination of the effectiveness of transformational leadership in the United States and Taiwan. Journal of Organizational Behavior, 26(3), 205-227.

Sternberg, R. J. (1999). Handbook of creativity. Cambridge University Press.

Straub, D., Loch, K., Evaristo, R., Karahanna, E., \& Srite, M. (2002). Toward a theory-based measurement of culture. Journal of Global Information Management, 10(1), 13-23.

Taras, V., Kirkman, B. L., \& Steel, P. (2010). Examining the impact of Culture's consequences: a threedecade, multilevel, meta-analytic review of Hofstede's cultural value dimensions. Journal of Applied Psychology, 95(3), 405-439.

Thomas, D. C., \& Ravlin, E. C. (1995). Responses of employees to cultural adaptation by a foreign manager. Journal of Applied Psychology, 80(1), 133-146.

Trompenaars, F. (1993). Riding the waves of culture: Understanding cultural diversity in business. London: The Economist Books.

Triandis, H. C. (1994). Culture and social behavior. New York: McGraw-Hill.

Triandis, H. C. (1995). Individualism \& collectivism. San Francisco: Westview Press.

Tyler, T. R., Lind, E. A., \& Huo, Y. J. (2000). Cultural values and authority relations: The psychology of conflict resolution across cultures. Psychology, Public Policy, and Law, 6(4), 1138-1163.

Walumbwa, F. O., \& Lawler, J. J. (2003). Building effective organizations: transformational leadership, collectivist orientation, work-related attitudes and withdrawal behaviours in three emerging economies. International Journal of Human Resource Management, 14(7), 10831101.

Walumbwa, F. O., Lawler, J. J., \& Avolio, B. J. (2007). Leadership, individual differences, and work related attitudes: A cross-culture investigation. Applied Psychology, 56(2), 212-230.

Yammarino, F. J., Dionne, S. D., Uk Chun, J., \& Dansereau, F. (2005). Leadership and levels of analysis: A state-of-the-science review. The Leadership Quarterly, 16(6), 879-919.

Yan, J., \& Hunt, J. G. J. (2005). A cross cultural perspective on perceived leadership effectiveness. International journal of cross cultural management, 5(1), 49-66.

Yaveroglu, I. S., \& Donthu, N. (2002). Cultural influences on the diffusion of new products. Journal of International Consumer Marketing, 14(4), 49-63.

Yukl, G. (1994). Leadership in organizations. Englewood Cliffs, NJ: Prentice-Hall. 


\section{Authors}

The contribution share of authors is as follows: G. Mustafa $75 \%$ and R. Lines $25 \%$.

\section{Ghulam Mustafa}

Ghulam Mustafa is an Associate Professor of Organization and Management at the Department of International Business, at the Norwegian University of Science and Technology (NTNU), Norway. He holds a PhD from Norwegian School of Economics (NHH) and an MPhil from the University of Bergen. His research interests include leadership, organizational behaviour and human resource management from a cross-cultural perspective.

Correspondence to: Ghulam Mustafa, PhD, Department of International Business, Norwegian University of Science and Technology (NTNU), Servicebox 1517, 6025 Aalesund, Norway, guma@ntnu.no

\section{Rune Lines}

Rune Lines is a Professor at the Department of Strategy and Management at the Norwegian School of Economics ( $\mathrm{NHH}$ ), Norway. He holds a doctorate in Business Administration. His research interests include strategy, change management, leadership, and employee emotions and values based reactions.

Correspondence to: Prof. Rune Lines, PhD, Department of Strategy and Management, Norwegian School of Economics (NHH), Helleveien 30, NO-5045 Bergen, Norway, e-mail: rune.lines@nhh.no

\section{Copyright and License}

This article is published under the terms of the Creative Commons Attribution - NonCommercial - NoDerivs (CC BY-NC-ND 3.0) License http://creativecommons.org/licenses/by-nc-nd/3.0/ 